\title{
El Perú hace 100 años: trabajo y migraciones
}

Wilma Derpich Gallo

\section{La migración: causas y contexto}

La movilización de la mano de obra a las nuevas regiones de asentamientos humanos correspondió en todo el siglo XIX al traslado de capitales (ejemplos Canadá y Australia) y a la extracción de recursos en otras zonas. Las migraciones siguieron un proceso turbulento y transformaron el espectro sociocultural en cada uno de los países donde se produjeron.

El desarrollo del capitalismo era impensable sin la navegación. A través de los mares se desplazaron hombres, capitales, recursos y mercancías. De Gran Bretaña a América cruzaron el Atlántico 199108 individuos. Para estos mismos años, de 1846 a 1850, salieron 36505 alemanes y 54595 japoneses.' A los EE.UU. llegaron hombres y mujeres de Gran Bretaña, Alemania. Francia, Escandinavia y Suiza. Antes fueron trasladados millones de esclavos negros que hicieron posible la expansión del sistema de plantaciones. ${ }^{2}$ Llegaron también peones de China para construir ferrocarriles principalmente.

Así sucedió también en el Perú. Mientras guano, lana, cuernos, azúcar y algodón salían de nuestros puertos a Europa, otros barcos traían negros, chinos, vascos, canacas o polinesios, ${ }^{3}$ alemanes e italianos.

El movimiento poblacional en el siglo XIX tuvo dos modalidades: colonos voluntarios en busca de futuro, como el caso de italianos a Argentina, por ejemplo. Y migrantes forzados, como los coolies chinos al Perú y los coolies hindúes para las plantaciones azucareras en la Guyana británica.

La migración china fue la más numerosa en el Perú. En veintisiete años arribaron oficialmente 92130 asiáticos, cuando Lima no pasaba de cien mil habitantes. Vinieron de Macao y Hong Kong. empleando algo más de tres meses de travesía, en condición de contratados. Por los mismos años trabajadores chinos salieron hacia Cuba, Australia, Panamá, los EE.UU. y Canadá. China representaba el $67 \%$ de la población mundial y con el tratado de Nanking de 1842 comienza a abastecer de brazos al mundo. Pero estaba prohibida la salida de mujeres y con ella bloqueada la extensión de la cultura china. Algunos agentes de emigración como el inglés James White quisieron canalizar la compra de mujeres chinas para conducirlas a las colonias británicas donde vivían trabajadores asiáticos, pero no fueron autorizados por el Foreign Office. Eso ocurría en 1854.

Durante los diez primeros años de migración china al Perú, llegaron 7718 chinos a laborar campos de azúcar y algodón e islas guaneras. En los 14 años siguientes (entre 1860 y 1874) la actitud contraria a esta migración fue mayoritaria. En este periodo se registraron 84412 asiáticos. Dichos migrantes ocuparon las escalas más simples en el trabajo agrícola, la extracción de guano y la construcción de ferrocarriles y recibieron maltratos y ataques, además de sufrir prejuicios raciales.

1 Entre 1816 y 1850 cerca de cinco millones de europeos abandonaron sus países de origen (Hobsbawm. E., p. 211 . The Age of Revolution). Entre 1850 y 1888, 22 millones de europeos emigraron.

2 Mannix and Cowley. Historia de la trata de negros. En cuatro siglos unos 15 millones de negros cruzaron el Atlántico hacia América.

3 Derpich Gallo. Wilma, Canacaso polinesios en e/Perúde/siglo XIX, junio, 1979, artículo. 
Hacia 1862 serán traídos a la fuerza (en verdad mediante robos y engaños) $4 \mathbf{3 4 0}$ nativos de las islas de la Polinesia, destinados al trabajo agrícola $y$ al servicio doméstico. Las veces que hubo contrato de por medio, el canaca recibía cuatro pesos al mes. Presiones diplomáticas y continuas demandas de misiones, terminaron prontamente con este proceso que pretendió rempla. zar al tráfico de asiáticos.

Las distintas migraciones recibidas en el Perú durante todo el siglo $\mathrm{XIX}$ respondían a la necesidad de solucionar la carencia de mano de obra para la costa. Teníamos en el país el "sentimiento" de la migración europea, pero en los hechos ésta fue insignificante. ${ }^{4}$ Los criterios y actitudes hacia los procesos migratorios se diversificaron la través de burdos e interminables debates) en dos corrientes: la tendencia utilitaria que buscaba asegurarse peones contratados y fue defendida por hacendados de toda la costa, a pesar de sus prejuicios raciales y de sus sueños por migrantes blancos. Querían seguridad en aras de la rentabilidad. En 1851, con Domingo Elías triunfa la voz de estos agricultores cuyo proyecto nacional estaba orientado a la economía de exportación. Y la otra corriente: la humanitaria, que era argumentada por quienes querian el desarrollo en términos industriales, buscando la destrucción de las relaciones señoriales en los Andes, aperturando el mercado nacional.

Ambas tendencias compartían un prejuicio mayor: la creencia en la inferioridad del indígena. En estas condiciones el chino fue la única alternativa. ${ }^{5}$ Cuando en 1874 el tráfico chinero finaliza, se hace evidente otra vez la carencia de brazos. Tres años después, la casa Olyphant intenta reabrir el negocio pero ya es tarde. Los hacendados tampoco optan por el trabajo tipo colono, que hubiera sido. junto a una política agresiva de atracción al emigrante. la posibilidad real de poblar la costa. Prefieren la seguridad del peón endeudado, del coolie chino alquilado, del indigena temporario $\mathrm{y} / \mathrm{o}$ parcelario. Mucho tiempo después. hacia finales del siglo, estos mismos propietarios de grandes extensiones eligirán nuevas modalidades de trabajo: el enganche del indígena. $Y$ paralelamente entregarán bajo yanaconaje o arrendamiento, parte de sus tierras a los chinos libres de contratos y recontratos. Del enganche serrano no nos ocuparemos. Anotaremos respecto al yanaconaje costeño encontrado en algunas regiones.

\section{De contratos, contratistas y yanaconas}

Hay cuatro momentos en las relaciones establecidas entre los trabajadores chinos y sus patrones. los agricultores costeños: a) el del régimen de contrato (principalmente por ocho años), periodo en el cual el peón asiático estaba obligado a su patrón y a cambio recibía cuatro pesos al mes, residencia en el galpón, atención médica (o del curandero), comida y ropa. La actitud del propietario hacia "sus" chinos era una mezcla de paternalismo con ciertos rasgos empresariales; $b$ ) el periodo de recontrato donde el agricultor endeudó al chino para obligarlo a permanecer en la hacienda. Los años de guerra con Chile muestran este caso en varias haciendas. Se puede relacionar esta situación con las huidas detectadas efectivamente en el sur cuando llegó el

4 En 1851 entraron 320 irlandeses con Rudolfo: en 1852, los primeros alemanes fueron al Pozuzo, quienes un año más tarde presentaban reclamos por abusos. En 1857 Cosme Schutz introduce 300 europeos más al Pozuzo. En 1860 llegan 320 vascos a Talambo. En 1892 llegan cien italianos a la selva de Chanchamayo.

5 Consultar tesis de Wilma Derpich Gallo: Introducción al trabajador coolie chino en el siglo $X I X$, Universidad Nacional Mayor de San Marcos, Lima, 1976 
ejército chileno. Hay dos razones: el chino recontratado estaba cansado y tenía experiencia de trabajo; al menos teóricamente quería independizarse. EI hacendado a su vez tenía más riesgos: debía regular el trabajo, calcular las pérdidas por fugas ${ }^{6}$ y asumir la tarea inconclusa en sus campos. En esta etapa la administración de la hacienda y el papel de los administradores fue preocupación permanente de los agricultores; $c$ / el periodo del contratista o agente chino de trabajadores asiáticos que se convierte en peligroso intermediario entre hacendados $y$ trabajadores; peligroso para el hacendado porque pasó a ser el verdadero dueño de los peones y quien reguló por tanto el régimen laboral. El contratista aparece en la correspondencia privada de cada hacienda y no deja de percibir la diferencia entre peones libres y los recontratados por él. El contratista fue además un capataz enriquecido y despiadado. En el norte, durante la guerra, el contratista fue un personaje importante; $c h$ la etapa del yanaconaje. En las haciendas y/o fundos aparecen los trabajadores como peones libres, pero analizando las cartas privadas se va descubriendo la realidad. El yanacón chino no firmaba contrato y compartía el producto hasta en un $25 \%$ con el hacendado. llustremos algunos ejemplos de este periodo posterior a la guerra con Chile, hacia 1887. En el valle de Huaura, la hacienda Caldera con 40 chinos libres de los cuales el $75 \%$ son yanaconas. El fundo Quipico, en el mismo valle, tenía doscientos chinos libres, algunos de los cuales eran yanaconas que partían el producto con el hacendado (el documento no dice cuantos eran "esos algunos"). En el valle de Supe, el Patao, encontramos 32 arrendatarios y 15 libres. En el Santa, es aún más notorio: en Tabón, por ejemplo, hay cien yanaconas; en Gallinazo. treinta; en Carrizal, veinte.

En los hechos, después de los sucesos de la guerra, el régimen de trabajo de los chinos cambió: aparecieron con más frecuencia contratistas chinos (enganchadores) y yanaconas $y / o$ arrendatarios. Claramente la estructura de la propiedad de la tierra sufrió una modificación. En la hacienda Cartavio de la Grace, por ejemplo, hacia 1888, los chinos alquilados debían hasta tres años de servicios. Habia entonces dos contratistas chinos que controlaban a treinta y siete trabajadores asiáticos. La gran propiedad extranjera hizo uso de los chinos combinando modalidades de trabajo, hasta el gran aluvión de peones serranos enganchados y finalmente, el periodo de proletarización rural.

\section{La participación popular}

Las corrientes migratorias cambiaron el panorama social en el Perú de preguerra. Contribuyeron a acentuar aún más los sentimientos contrarios a la unidad nacional, dependiendo de la situación que en la producción ocupara el emigrante. No pudo ser de otra manera: no estaban dadas las bases estructurales que permitieran una sociedad nacional. Los europeos venidos al Perú se establecerán como artesanos, comerciantes y operarios calificados: serán extranjeros respetados y respetables. De ellos la guerra obtendrá heroicas participaciones. Fueron ciudadanos del orden en quienes las palabras patriotismo y defensa de la propiedad, tenían sentido.

La población canaca (de la Polinesia) breve e insuficiente, destinada a la agricultura y al servicio doméstico, dejará huellas difíciles de ubicar por el momento.

La migración chilena, que trabajó los ferrocarriles y en menos escala, en

- Sobre el sistema de fugas o cimarronaje. que fue la expresión rebelde más importante de los chinos en el Perú, he propuesto algunas hipótesis en dos artículos publicados en las revistas Puente (1983) y Apuntes (1984). 
las islas guaneras, ha sido poco estudiada. Meiggs, el empresario constructor recurrió al roto chileno, prometiéndole y cumpliendo con un salario de 60 centavos al día en moneda chilena, más casa, comida y transporte. La concurrencia de fuerza de trabajo chilena al Perú se incrementó a mediados de 1868 y continuó por lo menos por cuatro años. Fuentes diversas la estimaban entre veinte y treinta mil chilenos. Pero tuvimos también ferrocarrileros bolivianos, especialmente para el tendido de rieles en el sur. Sin embargo el mayor prestigio para éstas lo tenían los chinos, que Meiggs utilizó sobre todo para la línea a La Oroya y a Chimbote. Sabido es que hubo mortandad elevada: ésta no elegía nacionalidades. Unos y otros morían de verrugas, de paludismo, y otras plagas. Peones bolivianos laboraron también en campos salitreros peruanos, a donde llegaron con sus familiares. ¿Qué actitud tuvieron estos hombres, chilenos y bolivianos, frente a la guerra?; ¿qué fue para ellos la patria en esos momentos de.confusión? Debe quedar claro que todos estos migrantes formaron el pueblo del siglo xix conjuntamente con el pueblo ¿nativo?... La guerra con Chile se vivió también en este pueblo desintegrado, no por causas "raciales" sino económico-sociales. Formalmente entonces el Perú hizo una guerra nacional. No olvidamos las excepciones naturales en todo proceso.

El campesino indígena, yanacona, aparcero, productor simple, comunero. constituye la multitud más importante de este pueblo oficialmente nacional. Alterna con la actividad minera, baja temporalmente a la costa. Sin indios. también los arrieros. Este sector del pueblo andino fue fundamentalmente inamovible. El indigena fue un hombre-hacienda y seguramente como tal respondió a la guerra.

En las ciudades costeñas, como murallas coloniales, bandoleros y vagabundos limitaban los caminos. El control interno de todo este pueblo, era entonces, en los años preguerra, ya un asunto delicado. La guerra evidencia el caos. Grafica un periodo, un largo tiempo de desorden. La participación popular en la guerra o a propósito de ella (que no es lo mismo) debe ser manejada en este contexto. Me refiero por ejemplo a los sucesos de Cañete en 1881 , a las huidas de los chinos para "engrosar las filas enemigas", a los saqueos a comerciantes chinos en Lima. ${ }^{7}$ y otros.

Dos de las expresiones populares más persistentes durante el siglo XIX. me refiero al bandolerismo $y$ al cimarronaje, se dieron independientemente de la guerra. El que sus protagonistas fueran algunas veces chinos fue circunstancial y más la expresión de una parte del pueblo frente al desgobierno, que una actitud étnica o un rechazo al Perú. Las teorías étnicas oscurecen el rostro y los motivos de la turba en una sociedad en crisis y preindustrial. En tanto la guerra con Chile ocurre en ausencia de una identidad nacional, la participación popular en ella no debe ser interpretada desde la óptica del patriotismo o fidelidad. Me arriesgo más bien a entender que para el caso de los indígenas en los Andes y de los chinos en la costa norte, primó la fidelidad al patrón.

Para los desocupados que al menos en el caso de Lima en 1876 eran 68121 personas ¿qué comportamiento podía esperarse? ¿Y para los sirvientes domésticos y ambulantes?

\footnotetext{
7 Encontré un manuscrito con las "reclamaciones de los súbditos chinos" al gobierno peruano. por las pérdidas sufridas por saqueos diversos de la tropa nacional en el Archivo del Ministerio de Relaciones Exteriores, 1892-95, Lima.

${ }^{8}$ Eran parte del pueblo, naturalmente, los trabajadores a domicilio. Sobre ellos y la multitud limeña debe consultarse "Masas urbanas y rebelión en la Historia", de Margarita Giesecke, Lima, Cedhip, 1970.
} 
Como fuera, las distancias entre pueblo ${ }^{8}$ y ciudadanía eran tan grandes como hoy. La reacción ante la guerra tuvo que ver como aquéllas.

No siempre el pueblo entero era parte de la turba, como quiso registrar Juan de Arona cuando habló de los sucesos que ha hecho famosos, es decir los de Cañete en 1881. Su interpretación del "odio de la turba peruana" contra los chinos por saberlos colaboradores de los chilenos, es un homenaje a la exageración que muchos otros autores (contemporáneos por añadidura) han reiterado. No descartamos el elemento racista en la turba, como un ingrediente más; resaltamos más bien en la forma típica de explosión contra el orden y la propiedad (saqueo de almacenes por ejemplo en varios momentos de la guerra), que toda turba ejecuta. Cada hombre y mujer del pueblo vivió la guerra. $Y$ ciertamente muchos de esos aguateros, lavanderas, peones ordinarios, guaneros, ferrocarrileros, campesinos, domésticos, celadores, ambulantes y mineros, tuvieron su versión de la guerra. Activaron en ella, obligados o como voluntarios. Las investigaciones aún tienen que esclarecer estas historias.

\section{¿Racismo y complot asiático?}

En los años anteriores a la guerra y especialmente desde 1870, los hacendados vivirán el fantasma del "complot asiático". En el lenguaje de la época aparece el odio racial como fenómeno explicativo de las fugas, revueltas, crímenes sociales, vagabundaje y otros. No sólo para explicar aquellas acciones protagonizadas por chinos, sino aquéllas de los indios y zambos.

Recordemos que a partir de 1870 la llegada de los chinos al país acusa un flujo muy alto (veamos un ejemplo: en 1871: 15461 coolies contra 4266 en 1868, o 450 en 1857); y que las presiones internacionales contra el tráfico de chinos, especialmente los de la Sociedad Antiesclavista de Londres. aunadas a las quejas llegadas hasta las autoridades chinas, habian ido en aumento. A nivel interno, eran numerosas las razones para experimentar este temor: en primer lugar un número elevado de los chinos habia terminado sus contratos y estaba a la deriva en búsqueda de otro porvenir y/o engrosando el ejército de desocupados ("los chinos libres son ahora un peligro", El Hera/do de Lima núm. 676, octubre, 1870). Todavía otro factor interno: las protestas de los chinos contra los abusos de sus patrones ("el asiático José Montero en la gestión de libertad de mis paisanos Ajan, Sinjó y Hasié, 1869, contra el patrón Marcelino Vargas en Chancay") adquirieron mayor peso en las cortes de justicia. Aparecieron incluso apoderados de los chinos y muchos abogados defendieron a los asiáticos contra los agricultores. No faltaron entonces voces de periodistas y escritores humanistas ("Ios asiáticos piden que se les considere como hombres, y no como bestias". El Comercio, marzo de 1869). que se alzaran a favor de la causa de los chinos. Por entonces, se suceden tumultos en algunos valles: Pativilca, Lurín, Santa. El cimarronaje o sistema de fugas está por esos años en proceso ascendente.

Resulta categórico para nosotros que toda protesta o expresión popular se vio e interpretó como producto del odio de castas o razas. ${ }^{9}$ Esta óptica abiertamente prejuiciosa no se dirigió sólo contra los chinos. Un periodista en El Comercio a propósito de la sublevación de los indios en Hualgalá en 1869, hablaba de "conflagración de castas en el país". Por cierto sin exhibir prueba alguna, pero con la seguridad de denunciar lo que constituia ya un te-

9 Los testimonios de vida que trabajamos desde 1983. con protagonistas limeños de los años treinta de este siglo. muestran claramente la existencia de prejuicios étnico-raciales de negros hacia indios, de indios hacia chinos, de blancos hacia indios, negros y chinos, de mestizos hacia negros, etcétera 
mor social compartido. Miedo explicable en momentos de crisis, que vivía una clase social. Como justificadas fueron también las diversas modalidades de protesta que vivió el pueblo. En 1876 el hacendado Lorenzo Arrieta del fundo Naranjal, denunciaba un plan de rebelión de todos los colonos asiáticos de Carabayllo Alto, señalando inclusive a líderes como Afú por habérsele encontrado dos revólveres. Hecho el testimonio, Afú fue dejado libre por carecerse de pruebas.

En este panorama acontece la guerra con Chile. Consecuentemente fue fácil encontrar traidores, fugitivos y colaboradores con el enemigo. Como sencillo resultó para los chilenos recrear su imagen de salvadores. Sin embargo, ni lo uno ni lo otro sucedió como característica general del proceso bélico. Bandos y delatores aparecen en todo tipo de guerras, independientemente de las diferencias étnicas, de los motivos de "raza" y aun de la situación de clase. 